\title{
Referencing Proper Names: Complementing the Analytic with the Phenomenological Approach
}

\author{
Arturo Leyva ${ }^{1,2}$ \\ ${ }^{1}$ Department of Teaching and Learning, Florida International University, Miami, Florida, United States \\ ${ }^{2}$ Department of Philosophy, University of Miami, Miami, Florida, United States
}

\section{Email address:}

aleyva@fiu.edu

\section{To cite this article:}

Arturo Leyva. Referencing Proper Names: Complementing the Analytic with the Phenomenological Approach. International Journal of Philosophy. Vol. 8, No. 3, 2020, pp. 75-81. doi: 10.11648/j.ijp.20200803.13

Received: July 19, 2020; Accepted: August 6, 2020; Published: August 10, 2020

\begin{abstract}
This essay relates to proper names and how they can refer to individual persons, animals, or objects. An initial response to this question was the classical descriptivist theory. This theory was introduced by Frege and Russell, and presented the idea that we can think about specific things only indirectly via descriptive thoughts. Kripke developed a series of powerful arguments against descriptivism and proposed a casual theory for the referring function of proper names. The main idea in the causal approach is in passing on a name and its reference from one person to another. Another interesting approach to consider is predicativism, or the idea that proper names are just a special kind of common noun and that their semantic function is to designate properties of individuals. These approaches - descriptive, causal, and predicative- open a set of perspectives regarding a philosophical analysis of proper names, but offer no overarching bigger picture; consequently, there can be no secure consensus. Therefore, this paper proposes a phenomenological alternative that takes these useful elements and adds the idea that, in referring, the way an individual experiences the world is essential. The idea implies a two-way picture of reference-fixing, where the name and the referent are not necessarily a duality. The name refers to an object, but the object is presented as having that name as an aspect. If no individual object or person is presented to us as having a particular proper name as an aspect, the name is meaningless and does not refer.
\end{abstract}

Keywords: Analytical Philosophy, Philosophy of Language, Referencing, Phenomenology

\section{Introduction}

The propositional approach to the world using subjects and the corresponding predicates based on ' $S$ is $p$ ', should ensure that the reference and the meaning in propositions is constituted clearly. In the case of specific individual things (e.g., proper names), some situations can go beyond the third-person perspective when the named object implies dynamic features, for instance, when choosing that a perspective is relevant, as in Frege's infamous example of 'Hesperus and phosphorus', or when a name itself conveys a subjectively interpreted meaning, as in Kripke's widely cited example of 'Jack the Ripper'. In such situations, the analytic duality of object vs. meaning and subject vs. predicate becomes less obvious. That is, this combination requires more detailed attention.

This topic attracted the attention of thinkers from Mill to Frege, Russell, Kripke and their students, and gave rise to theories of meaning (addressing its constitution) and theories of reference (analysing the truth values of propositions). This essay approaches and explores the nature and function of singular terms by proposing a descriptive theory of reference fixing to complement the analytic logic with the phenomenological access to the nature of consciousness. The thesis is that names can appear in some cases as a proposed or even imposed aspect to the referents and then operates like any other aspect that is being used for describing an object. The point is in the possible conceptual grasp of the name and object. The central research question is 'How is the referential act really being performed?'

\section{Charting Linguistic Dynamics}

\subsection{The Situation}

To some extent, nearly everybody wonders how it is 
possible to correctly fathom 'things' in 'reality' and then communicate with and understand each other. Traditional approaches operate through metaphysical 'universals', where, for example, an apple is determined in its appearance and processual dynamics by its 'appleness'. Universals refer to the not obvious but existentially active autonomy in objects. However, this idea may seem vague to many depending on the spirit of the time. Therefore, at the end of the 19th century, a turn-around towards analysing language set in (i.e., the 'linguistic turn'). This linguistic turn was the idea that linguistic elements determine any understanding of 'things' and finally the 'reality' that is being referenced. Hence, propositions came to the fore as propounded by Frege [1] and Russell [2]. Nevertheless, ambiguities in attribution called for more-precise fundamental theoretical distinctions. The linguistic turn needed to develop its own metaphysics to come to grips with belief ascriptions and reliable representations of the world. The sophisticated transcendental accounts of the conditions for secure experience developed in German idealism were countered by philosophers who felt the need to be more realistic in following natural science with its discoveries about speech production and the brain. The prevalent approach today is based on considering propositions (i.e., 'subject $S$ features predicate $p$ ') as the relevant basis in thinking and communicating. However, safeguarding the grasp of mental and communicative functions in the nooks and crannies of real life proved difficult in the propositional grid approach. This struggle led to ever more '-isms' as possible perspectives, which mirrored even more detailed functional subdivisions because linguistic entities are not at the very origin of cognitive and interactional processes. They are-as, for instance, Wittgenstein noted in his Philosophical Investigations [3],-more like traces that are shaped according to the actual causes, often abbreviated as 'meaning is use'. This postulates that causality must be material and entail its consequences. In approaching mental processes and formally handling their traces, the machine metaphor is still en vogue, but this procedure has weak points. Its effects become particularly noticeable in situations for some individual objects (appearing in the propositional approach as proper names) and their own specific way of being that need to be considered adequately. In his Naming and Necessity, Kripke [4] reminded the community of analytic philosophers that what governs handling names is the process as regards content and that one need not be afraid of essentialist aspects because they are semantically constitutive, whether one likes it or not. For example, the action of choosing a perspective is influential as in Frege's [1] 'Hesperus and phosphorus' or when the name suggests meanings to the processing mind, as in Kripke's [4] 'Jack the Ripper'. Kripke's [4] view that names operate as rigid designators of the same object in every possible world concerns the identification of the referent for others, but not the dynamics in considering the actual identity of the referent itself. The connection between name and referent, which does not necessarily set up an easily separable duality, is the issue being addressed in this short essay.

\subsection{Methodological Considerations}

Considering the profound entanglement between language use and real life, the question of how sociolinguistic reality could conceptually be contained in a way that does not leave some gaps is interesting in principle. The analytic philosophic approach is usually adopted to address questions of reference. However, it is not certain that this is the best path to resolving the issue, which is to completely understand how the referential act is

being performed. Analytic philosophy as a way of proceeding is somewhat one-eyed as a result of being based on fundamental assumptions that have a self-limiting effect on a possible grasp of reality. Investigations as to the fundamental assumptions of analytic philosophy are remarkably scarce, and even more so concerning its tacit presuppositions. Collingwood [5] criticized this topic in some detail by observing that fundamental beliefs were not clarified. Beaney [6] offered a profound overview. Analytic philosophy and phenomenology have a shared history insofar that both originated in the same milieu and sought to overcome idealist obscurantism in the struggle to be precise and clear [7]. Husserl was in contact with Frege and his ideas were also familiar to Russell and Wittgenstein [7, 8]. Differentiations between their views came later, but a mutual influence was always present [7]. In the 1970 s and 1980s, several thinkers pointed out that the formal relationship between mental states cannot be a first-person perspective, which is essential for consciousness [8]. The irony is that analytic philosophy currently offers a complex theory of presuppositions (for an overview [9], but is only a theory of the conscious assumptions that may enter the considerations of a subject matter. In analytic philosophy, it is fairly obvious that what is not conscious cannot be talked about. Within that paradigm, therefore, it is impossible to address the effects of presuppositions at the scale of human beings. The fact that this issue can be resolved by knowing that an object resides in a category, through which strictly everything is being thought, appears in analytic philosophy only in a reduced form, that is, as a categorical theory for contemporary mathematics and theoretical computer science [10]. Because of this reduced scope for its own operative capacities, mainstream analytic philosophy cannot be the best candidate for addressing the act of reference. Not surprisingly, alternative approaches were proposed recently, in particular, some approaches based on the phenomenological approach. Rowlands [11] argued in terms of situated cognition, especially as opposed to the computationalist view of the mind, which cannot account for autonomous features that characterize a truly human perspective using all organic functions in a processual relationship with reality. Potrč and Šuvaković [12] formulated another phenomenological proposal addressing the referential act with an explicit critique of approaches in ordinary language philosophy. The conceptual groundwork for the phenomenological approach was essentially developed by Edmund Husserl, whose legacy was recently reformulated by Zahavi [13], specifically in the context of the contemporary debate of realism versus idealism, internalism versus externalism, new naturalism conceptions in the cognitive 
sciences, and speculative realism.

\section{Approaching the Reference of Proper Names}

In everyday understanding, proper names correspond roughly to what are usually called 'names'-for instance, 'Vladimir Putin', 'Berlin' or 'Mount Everest'. At first glance, names seem to be syntactically simple expressions that do refer to specific objects or individuals, or at least are meant to actually refer to them. Thus, what kinds of objects can be used as referents? Is 'Santa Claus' allowed? Is 'Einstein's theory of relativity' allowed? In any case, there are sometimes linguistic acts of referring to these objects. However, what does 'exist' really mean? The 'official opinion' on this question may not correspond to reality in the complete sense or to the opinion of the population at large. Finally, the question is what is relevant? Language, including what appears as 'names', is a communicative instance of mediation based on the mental instance of thinking, where non-thinking (in the sense of blindly acting out or following a dogma) also has an effect on language.

The referential act of using proper names can be approached from different perspectives, which have their specific consequences. In actual reality, a situation may call for one or more of these approaches and these perspectives may even overlap. For starters, in the literature on references, there is a recurring, but yet misleading, flowery phrase, that is, "words are themselves capable of "hooking onto" things in the world' [14], as if that would occur on its own. After all, no term ever acts, because the act of reference occurs-in accordance with Saussure's [15] famous distinction-in context-dependent and often spirited 'parole' (i.e., the concrete use of language in actual utterances), not just structural 'langue' (i.e., the system of language that precedes the use of language and makes speech possible at all). Indeed, language is not a structure that controls people's minds by dint of new experiences. It is in continuous evolution; therefore, new nuances are linguistically embodied all the time. Forms of order and, hence, conventions do arise, but in a flexible way. For example, nobody knew beforehand that 'Edward Snowden' and 'Julian Assange' would become symbols of whistleblowing martyrdom or that a verb such as 'to Google' would become popular. Formal rules - such as saying that "to google" belongs to a coerced descriptive sort of term [16]—rise like shadows only after the events. This constitutes a subject matter for academic investigation to understand the interconnections between phenomena. How can these results be practically helpful for those who must tackle life and are continuously compelled to invent new expressions for getting along with each other? The point is that we all do so by means of referencing. Open access publications are useful for facilitating this increased awareness because society can function more smoothly when it is more transparent.

\subsection{Possible Analytic Views of Reference}

Systematically speaking, multiple perspectives can be used when seeking a complete coverage of the process of referencing: that is, from outside (which leads to models of description); from inside (leading to models of character); from external history (leading to models of causality and predicativism); and from internal human purpose (in models of intention).

In comparing each of these four cases, the presentation will be carried out in two stages in section 3.2: from the perspective of analytic philosophy and from an alternative complementary perspective.

\subsubsection{The Descriptivist Approach}

Frege [1] and Russell [2] introduced the classical descriptivist theory, which presents the idea that we can think about individual things only indirectly via descriptive thoughts. From this perspective, words and names can be referenced because their descriptive characteristics are associated with specific contents, which allows the specific object or individual referenced to be identified. For example, following Frege [1] the name 'Aristotle' can be considered by associating it to properties such as: a Greek philosopher, a teacher of Alexander the Great, a person born in Stagira, a student of Plato, and so on. Concerning proper names, Frege [1] also introduced the conceptual difference between reference or referent ('edeutung') and what the name expresses, that is, its meaning or sense ('sinn'). Russell [2] distinguished 'logical' proper names (e.g., indexicals like 'there' or 'this') from 'ordinary' names, which he considers as abbreviated descriptions (where 'Aristotle' is shorthand for what Frege considers the meaning or sense of the name). In both cases, to reference a proper name clearly, we do not need to point at your pet aardvark Napoleon if someone observes that 'Napoleon has a nice burrow'.

\subsubsection{The Character Approach}

The character approach is centred on the idea that words are used in acts of referring while following accepted rules of reference. This occurs when the context implies repeatable elements that serve as a paradigm for the identification of the referent through the suitable expression. For example, Kaplan [17] noted that indexicals have character and content. The content of an indexical is the object being referred to, while character is the linguistic rule for the indexical to determine the content (meaning) in a context. According to Kaplan [17], indexicals have a variable character insofar as their content is determined by the different contexts in which they are used. However, proper names have a stable character because their rules of use are not context- dependent. Kaplan [17] represented character by using their function from a possible context to the contents. Therefore, for proper names to fit this theory, Kaplan [17] saw the need for a set of 'syntactically distinctive' constants and semantic rules for the use of these constants, which would force them to have a stable character and a stable content in every context. While context may play some role in Kaplan's theory of proper 
names, it is secondary and indirect because it only serves to help disambiguate them. Following Kaplan [17], for example, if somebody says 'Napoleon is large' while holding your pet aardvark, it is likely that the person is referring to your domesticated insect-eating mammal and not the former emperor of France. However, the reference of a name is determined by the origin of the name and not by its context.

\subsubsection{The Causal Approach}

The main concept of the causal approach is in the passage of a name and its reference from one person to another. From this perspective, words allow references through their association with communications that lead back to an original use or to some sort of 'baptism' when used as a referent [4]. For example, after Napoleon was baptized and he became the French emperor, his name and referent was then 'passed from link to link' until the receivers understood it as rigidly referring to a particular individual [4]. Thus, the emperor Napoleon's name is a rigid designator under the condition that the receiver of the name must use it with the same reference as it was used historically in the communicative chain. Therefore, giving your pet aardvark the same name as Napoleon would not satisfy this condition [4]

\subsubsection{The Predicative Approach}

The predicative approach complements the causal view by considering predicates as causing linguistic patterns. In the analytic tradition, names and predicates are considered as bits of language with different semantic functions. The latter refers while the former attributes properties or classifies individual objects into kinds. However, some philosophers contend that this difference is not fundamental and that names are really predicates. Thus, predicativism is the view that names are predicates in all their uses [18]. In general, predicativism proposes that the semantics of names are not essentially different from that of common nouns like 'aardvark' because they also express a property of the named object. More specifically, names express the property of having that particular name.

\subsubsection{The Intentionalist Approach}

Broadly speaking, the intentionalist approach considers that the referent of an utterance is fixed by the speaker's intention. Therefore, the relationship between the speaker's

For more detailed discussions on predicativism, and for an introduction to this perspective, see [18-21].

intention and the referent of the name is constitutive; that is, the speaker intends to fix the name with its referent. Intentionalists consider that the context plays an evidential role and is not constitutive of the fixed reference. The recipient's interpretation of a name's referent might be correct given the context, but might still be incorrect by not matching the speaker's intention [22]. For example, a friend can state 'Napoleon was angry' in reference to the French emperor while sitting in your living room watching you sitting beside your pet aardvark 'Napoleon'. The referent you will likely take the name to be about, that is, your pet aardvark, does not correspond to what your friend is referencing. According to anti-intentionalism, various aspects of the conversational context, such as the presuppositions, purposes and shared beliefs of the participants, fix the content of the of the utterance [22].

\subsubsection{A Summary of the Analytic Perspectives of Referencing}

The analytic approach opens up a set of perspectives regarding philosophical approaches to proper names, but it offers no overarching bigger picture. Consequently, there can be no secure consensus. However, some of these perspectives do not exclude, but in contrast imply other perspectives to some degree. Therefore, there are elements in of some perspectives that can be useful in other perspectives.

Regarding the descriptive approach, all descriptive theories include some form of descriptivism, that is, the idea that descriptive thoughts are used when thinking about an object. The thought is related to the object itself or indirectly to the thinker through some descriptive kind of thinking. Descriptive thoughts can be built up from simpler parts or it can be part of a complex compositional result.

Even Kripke [4] observed that descriptive theories are applicable at the moment of the initial baptism.

The character approach asserts that when analysing a name and its referent, the accepted rules of using a proper name must be considered, which pertains especially to the predicative aspect.

The concept of the causal approach is that a name and its referent must be used in a historically correct way and that the receiver of a name must use it with the same reference as it was used in the past, otherwise successful communication is not feasible.

In the predicative approach, the individual's active participation in fixing a name and its referent is important. For example, when there is a superhero commonly described as the master of the oceans who can manipulate its tides and movement, communicate with aquatic animals, swim at superhuman or superanimal speeds, he then unsurprisingly is called Aquaman. This example shows that the one-way perspective of questioning whether a name refers to an object or individual may also be an active participant in the namefixing process, just as the object itself may become clear through other descriptions.

Finally, the intentional approach addresses the influential ambiguities of natural language. For instance, two or more different names can refer to a single object (e.g., when translating a word from one language to another) or a single name can refer to two or more different objects (e.g., Napoleon possibly refers to the French emperor or your pet aardvark). A single reference can have two or more conforming names (e.g., the evening star Venus may indicate the western horizon to a sailor shortly after sunset or the eastern horizon to another sailor shortly before sunrise). However, a single reference may also have two or more names that represent it (e.g., the most popular sport in the world is called football in the United Kingdom and soccer in the United States). The way individuals experience the world 
is important in referencing an object. This

experience cannot be easily approached in the analytical tradition. Thus, some alternatives to overcome this issue are considered in this essay.

\subsection{Proper Names as Phenomenological Aspects}

There are different interpretations of what phenomenology refers to; therefore, the general idea needs to be clarified. In approaching consciousness and its awareness of phenomena, it is helpful to consider that objects in material observations have (or rather, hide) a backside, while thoughts reveal all their content. However, what the thinker is addressing due to his or her cultural habits, beliefs, training or interests may have a widening or a limiting effect.

The phenomenological perspective used here analyses 'givenness' as in the perceptual, imaginative or recollective dimension, and explores its 'essential structures and conditions of possibility [23]. The phenomenal or intentional directedness is understood here as an activity that directs or guides awareness towards the aspects of a 'region of the world' [11], which is then presented as being a certain way.

\subsubsection{The Nature of Language in Phenomenology}

Inkpin [24] took a phenomenological approach to language and argued that it is not a conveyor of mental acts, but rather, it is 'language in the world' or an instrument that assists in world disclosure and facilitates the practices by which we live. Language is an instrument that allows us to make features of the world intelligible (i.e., the presentational mode of instrumentality) and allows us to perform specific tasks (i.e., the pragmatic mode of instrumentality). Inkpin [24] labels his approach to language as a 'minimalist phenomenology', mainly due to his setting aside its transcendental 'touch' of the grounding of being.

In general, in analysing language, Inkpin [24] is arguably right to focus on the experience of its use in the importance of world disclosure and in our practices. However, his 'minimalist phenomenology', where language reveals the world as being present in a certain way or serves as a mode of presentation, is based on a traditional model of intentionality, where something seems to be lacking. In this context, Rowlands [11] seems to be right to argue that the traditional tripartite model of intentionality-act, object and mode of presentation-is limited because it identifies the mode of presentation only with empirical modes or aspects of presentation. Therefore, the empirical modes of presentation or that of which we are aware is the sole mode of presentation. In contrast to Inkpin [24], Rowlands [25] writes that there must be an additional mode of presentation, which he calls the transcendental mode of presentation. This mode connects the mental act and the intentional object of that act by setting the conditions that an object must meet to qualify as falling under specific aspects, and where particular aspects become the intentional object. However, in the sense of the investigation presented here, language cannot be a transcendental mode of presentation because it is objectifiable. Thus, language is something of which we are aware rather than something in virtue of which we are aware.

Within this picture of intentionality, the argument pursued here is that proper names are aspects of parts of the world that we are aware of due to their objectifiable nature. However, the transcendental mode of presentation or intentional directedness is simultaneously understood as an activity that directs or guides awareness towards the aspects of a 'region of the world' Rowlands [11], which is then presented as being a certain way.

\subsubsection{Subjective Perspectives and Objective Properties}

Following Rowlands [11], the content of an intentional act can be expressed in the form of a description and its object is that which satisfies this description. The empirical mode of presentation for the object is the content expressed in its corresponding description. For the object to match its contentspecifying description, we are aware of the object's aspects. However, these aspects are not the same as the object's objective properties. These aspects are intentional objects of consciousness. As aspects are the ways in which objects are presented to us, they are not objective objects of consciousness. Therefore, an aspect of an object presented to a person may not correspond with the objective property of the object. Rowlands' [11] proposal requires the intentional activity of a person for an object to have aspects, but there is no necessary condition of an object to have properties (i.e., the intentional activity may even be imaginary, but nonetheless effective). Thus, aspects are not identical to objective properties. For example, a basketball may present itself as round from some distance, even if it is low in air and a portion of it is flat as it lies on the gym floor, or it may present itself as dark orange in colour when it is officially brown. In addition, individuals could play basketball their entire life without the basketball ever being presented to them as having one of its most important objective properties, that is, it requires $8 \mathrm{lbs}$ of air pressure per square inch. In an analytic approach, such aspects usually provoke very complicated linguistic forms.

\subsubsection{Specifics of People'S Names}

People's names function as one of the aspects of which we are aware when we engage in an intentional activity of revealing an object as being in a certain way. In contrast to Frege [1] consideration of the name 'Aristotle' by associating it with properties, this proposal asks the reader to consider a human being that is revealed to us as a

philosopher born in Stagira, the teacher of Alexander the Great, a student of Plato, and being named Aristotle. Within this picture of intentionality, the traditional duality disappears between the name and the description when analysing a referring proposition. Names do not function as a link to the referent, as they are one of the parts of the compositional descriptions that individuate the object through the empirical mode of presentation. In other words, 'Donald Trump' does not refer to the individual that, for example, is 'the 45 th president of the United States'. Rather, 'Donald Trump' and 'the 45th president of the United States' are empirical aspects that result in a compositional description based on how the individual is presented to us. 


\subsubsection{The Essential Intentional Core}

Finally, regarding this matter, the 'non-eliminable intentional core' of the act or the transcendental mode of presentation is phenomenal consciousness, which not only represents the experiential component through which we are aware, but also directs our awareness towards aspects of the experience of which we are aware Rowlands [11]. This mode of presentation cannot be analysed as an object because it would become empirical and require another mode of presentation where this can be done. For our purposes, the use of proper names as perceived as an unobjectifiable complex relationship between personal history, memory, culture, social structure and general language use and rules, may be the structure where individuals of whom we are aware are presented to us as having a proper name as an aspect.

\subsubsection{The Unifying Quality of Phenomenological Reference-Fixing Descriptions}

This proposal implies a two-way reference-fixing description, where the name and the referent are not necessarily in duality. The name refers to an object, but the object is presented as having that name as an aspect of itself [26]. If no individual object or person is presented to us as having a particular proper name as an aspect, its name is meaningless and does not act as a reference. However, names are not necessarily arbitrary in nature. As Brédart [27] observed, surnames like 'Baker', 'Cook', 'Farmer', or 'Fisher' probably stemmed from ancestors who historically practiced these professions. This characteristic of some names shows that the name does not necessarily identify an individual and refer to him or her. In this case, the aspects of the object other than its name may participate in this two-way reference-fixing description.

\section{Conclusion}

This brief investigation showed that the mainstream analytic approach to the problem of reference is useful for details, but it lacks an overview of reality in a wider sense due to its presuppositions concerning the nature of language. Nevertheless, the analytic and phenomenological perspectives have a shared history, which has been outlined briefly. A mutual understanding can smooth the path towards complementing the analytic approach with the phenomenological perspective, which focuses on the idea that consciousness is not unseizable and merely subjective, but objectively a mirror of reality (i.e., the conceptual basis in the contemporary context was outlined by Zahavi [13]. Some connecting points between the analytic and the phenomenological perspectives were identified: that is, the basically descriptive approach, which can reach into personal participation and an open dialogue. Obviously, both approaches have their strong and weak points. However, approaches that complement each other instead of remaining entrenched can strengthen clarity in contrast to the divide between analytic and continental philosophy, which was unfortunately normal until recently.

\section{Conflict of Interest Statement}

The author declares that the paper was conducted in the absence of any commercial or financial relationships that could be construed as a potential conflict of interest.

\section{References}

[1] Frege, G. (1892). ‘Über Sinn und Bedeutung,' Zeitschrift für Philosophie und philosophische Kritik, 100 (1), pp. 25-50.

[2] Russell, B. (1917). 'Knowledge by Acquaintance and Knowledge by Description,' Proceedings of the Aristotelian Society, 1910-1911. Reprinted in Mysticism and Logic. London: George Allen \& Unwin Ltd. Totowa, NJ: Barnes \& Noble Books, 1951, pp. 152-167; pagination adopted according to the latter publication.

[3] Wittgenstein, L. (1953). Philosophical Investigations. Oxford: Basil Blackwell. Zahavi, D. (2007). 'Killingthe Straw Man: Dennett and Phenomenology,' Phenomenology and the Cognitive Sciences 6 (1-2), pp. 21-43.

[4] Kripke, S. (1980). Naming and Necessity. Oxford: Basil Blackwell. Ludlow, P. (2018). 'Descriptions,' in E. N. Zalta (ed.) The Stanford Encyclopedia of Philosophy (Fall 2018 Edition), pp. 96.

[5] Collingwood, R. G. (1933). Essay on Philosophical Method. Oxford: Clarendon. Elugardo, R. (2002). 'The Predicate View of Proper Names,' in: G. Preyer and G. Peter (eds.) Logical Form and Language. Oxford: Oxford University Press, pp. 467-503.

[6] Beaney, M. (2013). 'The Historiography of Analytic Philosophy,' in: M. Beaney (ed.) The Oxford Handbook of The History of Analytic Philosophy. Oxford: Oxford University Press, pp. 42-60.

[7] Moran, D. (2001). 'Analytic Philosophy and Phenomenology,' in: S. Crowell, L. Embree, and S. J. Julian (eds.) The Reach of Reflection: Issues for Phenomenology's Second Century. London: Electron Press, 2001, pp. 409-433.

[8] Walsh, P. J. and Yoshimi, J. (2019). 'Philosophy of Mind in the Phenomenological Tradition,' in: A. Kind (ed.) Philosophy of Mind in the Twentieth and Twenty-First Centuries: The History of the Philosophy of Mind, Vol. 6. New York: Routledge, pp. 21-51.

[9] Beaver, D. I. and Geurts, B. (2011). 'Presupposition,' in: E. N. Zalta (ed.) The Stanford Encyclopedia of Philosophy (Winter $2014 \quad$ Edition). Available at https://plato.stanford.edu/entries/presupposition/ (30 April 2019).

[10] Marquis, J.-P. (2015). 'Category Theory,' in: E. N. Zalta (ed.) The Stanford Encyclopedia of Philosophy (Winter 2015 Edition). Available at https://plato.stanford.edu/entries/category-theory/ (30 April 2019).

[11] Rowlands, M. (2010). The New Science of the Mind: From Extended Mind to Embodied Phenomenology. Cambridge: MIT Press. Russell, B. (1905). 'On Denoting,' Mind 114, pp. 479-493; 456, pp. 873-887 (orig), pp. 183, 186.

[12] Potrč, M. and Šuvaković, M. (2016). 'Referential Zero Point,' Journal of Art and Media Studies (9), pp. 13-22. 
[13] Zahavi, D. (2017). Husserl's Legacy: Phenomenology, Metaphysics, and Transcendental Philosophy. Oxford: Oxford University Press.

[14] Michaelson, E. and Reimer, M. (2019). 'Reference,' in: E. N. Zalta (ed.) The Stanford Encyclopedia of Philosophy (Spring 2019 Edition).

[15] Saussure, F. de (1916). Cours de linguistique générale. Paris: Payot. Saussure, F. de (1998). 'Cours de linguistique Générale,' in C. Bally and A. Sechehaye (eds.) R. Harris (trans.) Course in General Linguistics. New York: Open Court.

[16] Ludlow, P. (2018). Descriptions In E. N. Zalta (Ed.), The Stanford encyclopedia of philosophy. Stanford: Metaphysics Research Lab, Stanford University.

[17] Kaplan, D. (1989). 'Demonstratives,' in: J. Almog, J. Perry, and H. K. Wettstein (eds.) Themes from Kaplan. Oxford: Oxford University Press, pp. 481-564.

[18] Fara, D. (2015). 'Names are predicates,' Philosophical Review 124 (1), pp. 59-117.

[19] Elugardo, R. (2002). The predicate view of proper names. In G. Preyer \& G. Peter (Eds.), Logical form and language. Oxford [UK]: Oxford University Press, pp. 467-503.

[20] Martí, G. (2017). 'Names, Predicates, and the Object-Property Distinction,' in: M. De Ponte, and K. Korta (eds.) Reference and Representation in Thought and Language. Oxford: Oxford University Press, pp. 14-19.
[21] Matushansky, O. (2008). 'On the Linguistic Complexity of Proper Names,' Linguistics and Philosophy 31 (5), pp. 573627.

[22] Montminy, M. (2010). 'Context and Communication: A Defense of Intentionalism,' Journal of Pragmatics 42 (11), pp. 2910-2918.

[23] Zahavi, D. (2007). Killing the straw man: Dennett and phenomenology. Phenomenology and the Cognitive Sciences $6(1-2): 21-43$.

[24] Inkpin, A. (2016). Disclosing the World: On the Phenomenology of Language. Cambridge: MIT Press, pp. 17, 224.

[25] Rowlands, M. (2018) Disclosing the world: Intentionality and $4 \mathrm{e}$ cognition. In A. Newen, L. De Bruin, \& S. Gallagher (Eds.), The Oxford handbook of 4E cognition (p. 335-352). Oxford, UK: Oxford University Press.

[26] Stivers, T., Enfield, N. J., and Levinson, S. C. (2007). 'Person Reference in Interaction,' in: N. J. Enfield and T. Stivers (eds.) Person Reference in Interaction: Linguistic, Cultural, and Social Perspectives. Cambridge: Cambridge University Press, pp. 1-20.

[27] Brédart, S. (2017). 'The Cognitive Psychology and Neuroscience of Naming People,' Neuroscience and Biobehavioral Reviews 83, pp. 145-154. 